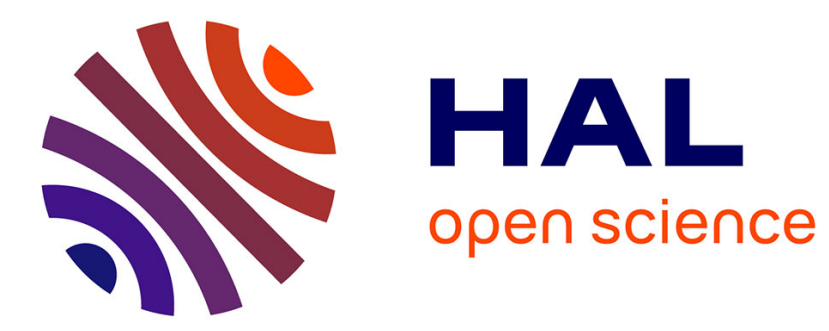

\title{
Generation of static electricity during fluidisation of polyethylene and its elimination by air ionisation
}

\author{
J Revel, Cendrine Gatumel, John A. Dodds, J Taillet
}

\section{To cite this version:}

J Revel, Cendrine Gatumel, John A. Dodds, J Taillet. Generation of static electricity during fluidisation of polyethylene and its elimination by air ionisation. Powder Technology, 2003, 135 (SI), pp.192-200. 10.1016/j.powtec.2003.08.015 . hal-01649524

\section{HAL Id: hal-01649524 \\ https://hal.science/hal-01649524}

Submitted on 7 Nov 2019

HAL is a multi-disciplinary open access archive for the deposit and dissemination of scientific research documents, whether they are published or not. The documents may come from teaching and research institutions in France or abroad, or from public or private research centers.
L'archive ouverte pluridisciplinaire HAL, est destinée au dépôt et à la diffusion de documents scientifiques de niveau recherche, publiés ou non, émanant des établissements d'enseignement et de recherche français ou étrangers, des laboratoires publics ou privés. 


\title{
Generation of static electricity during fluidisation of polyethylene and its elimination by air ionisation
}

\author{
Jérôme Revel ${ }^{\mathrm{a}, \mathrm{b}}$, Cendrine Gatumel ${ }^{\mathrm{a}, *}$, John A. Dodds $^{\mathrm{a}}$, Joseph Taillet ${ }^{\mathrm{b}}$ \\ ${ }^{a}$ Laboratoire de Génie des Procédés des Solides Divisés, UMR CNRS 2392-École des Mines d'Albi-Carmaux-81013 Albi cedex 09, France \\ ${ }^{\mathrm{b}}$ Valitec-8, rue de l'Est-92100 Boulogne Billancourt, France
}

\begin{abstract}
Static electricity is the cause of many problems in the process industries, in particular, when handling powders and granules. The methods usually used to reduce static electricity involve the addition of antistatic agents, the increase of relative humidity or ionisation. But these solutions can give rise to other problems. The purpose of this paper is, first, to study the kinetics of electrostatic charging of polyethylene granules and powders in a fluidised bed and, second, to study the elimination of the static electricity using the same particles with a special supersonic injector producing a neutral cloud of positive and negative ions. The experiments involve taking samples of particles at various times and various locations in the bed and measuring the charge-to-mass ratio by means of a Faraday pail connected to an electrometer. It is found that the electrostatic charge increases during fluidisation up to a limiting value. Concerning the charges elimination, it is shown that ions ejected from the eliminator cannot penetrate into the bulk of particles. Only the particles on the upper surface of the bed are discharged. Thus, the efficiency of the supersonic injector for overall charge neutralisation depends on the movement of the particles in the bed and, in particular, the rate of renewal of the upper surface of the fluidised bed.
\end{abstract}

Keywords: Fluidisation; Polyethylene particles; Particle charging; Charge-to-mass ratio; Static elimination; Ionisation

\section{Introduction}

The first references to static electricity in fluidised beds go back to the early 1950s [1] and since that time, many studies have been made on the influence of static electricity on the fluidisation of insulating particles. It is found that electrostatic charges give rise to particle-wall and interparticle interactions of a magnitude such that they can affect the hydrodynamics of the fluidised bed $[2,3]$. This, for example, is a disadvantage for heat transfer between dielectric particles and an immersed heat exchange surface [4]. Experimental work performed on static charge elimination has shown that the addition of a small proportion of fines to a fluidised bed leads to the splitting of agglomerates and to the disappearance of a layer of particles clinging to the wall [5]. Moreover, fluidising with a strongly humidified gas can be an efficient way to eliminate electric charges [6,7]. For example, a relative humidity of $70 \%$ suppresses hydrodynamic problems and the agglomeration of polystyrene

\footnotetext{
* Corresponding author.

E-mail address: gatumel@enstimac.fr (C. Gatumel).
}

particles [8]. However, these methods can give rise to other problems. For example, it is not always possible to add fines in a fluidised system if the particles have to remain clean or monodispersed. Furthermore, if the relative humidity is too high, liquid bridges can form and lead to the formation of agglomerates. Air ionisation does not have these disadvantages, but little work has been performed on the application of this method to fluidised beds. The aim of this paper is first to study the kinetics of electrostatic charging of polyethylene granules and powders in a fluidised bed, and second to study the elimination of the static electricity on these products using a special supersonic injector producing a neutral cloud of positive and negative ions.

\section{Experimental apparatus and procedure}

The experimental apparatus (Fig. 1) is a fluidised bed made from a 10 -cm diameter and 30-cm-high Altuglas ${ }^{\circledR}$ column. A 50-cm diameter earth-connected metal cylindrical section (disengagement zone) tops it. The humidity and the temperature of the air are measured by two probes located downstream from the metal fluidisation distributor 


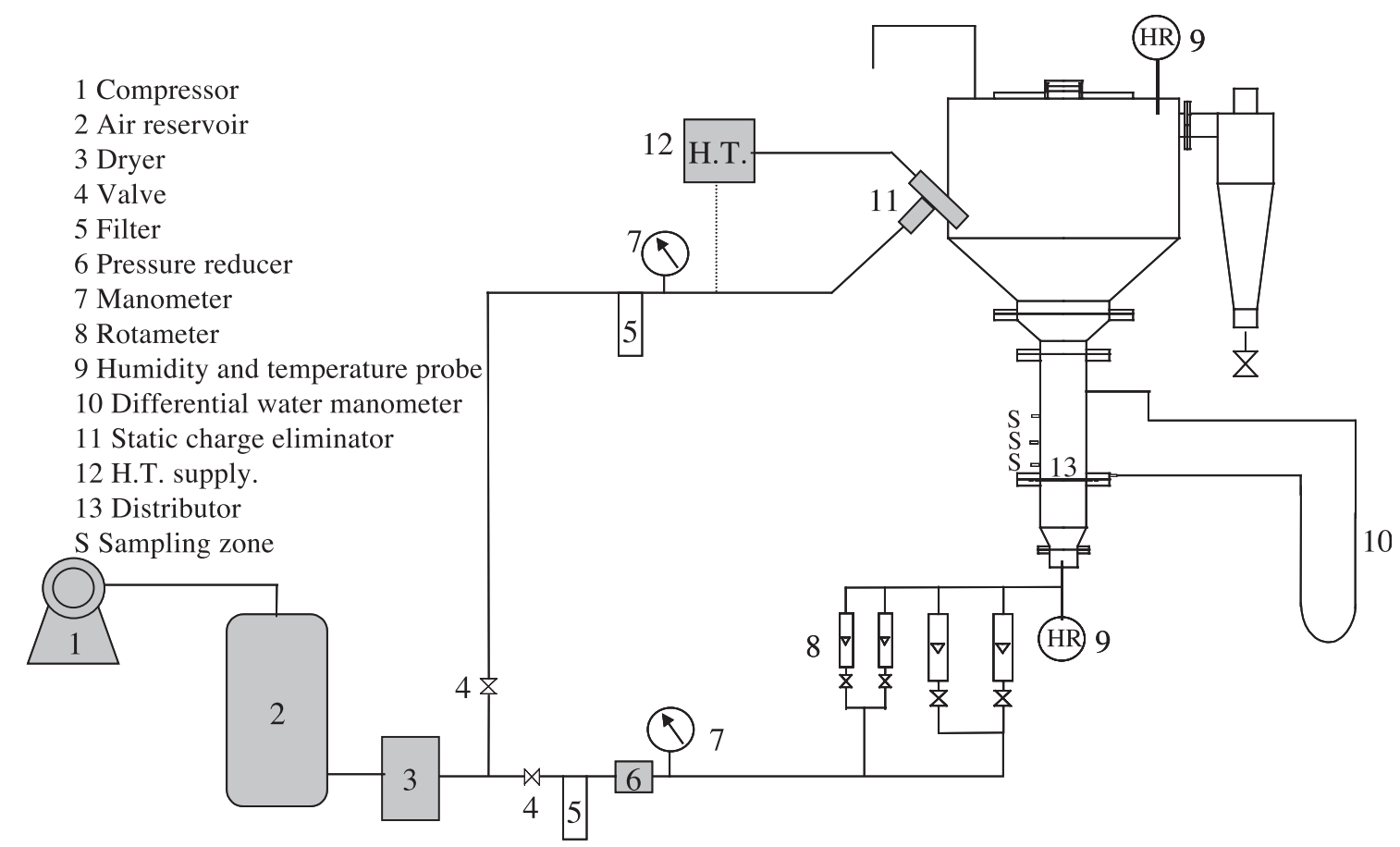

Fig. 1. Experimental apparatus.

and at the top of the fluidised bed. The experiments were carried out at room temperature (between 21 and $27{ }^{\circ} \mathrm{C}$ ), with a relative humidity less than $5 \%$ inside the bed so as not to promote electrostatic discharging. The pressure drop through the bed was measured with a differential water manometer.

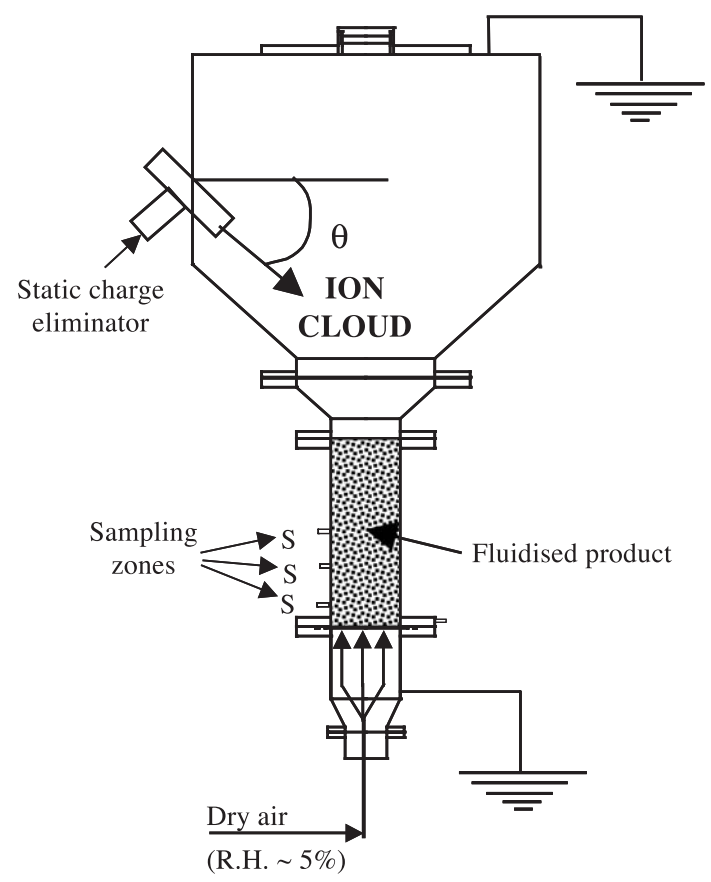

Fig. 2. Location of the eliminator.
The electrostatic charge eliminator is an industrial device produced by Valitec ${ }^{\circledR}$. It is designed to inject a balanced current of positive and negative charges into large mass flows of fluidised bulk material and can be operated in an explosive atmosphere. The probe comprises a metal section fed with slightly humid compressed air (dew point less than $-20{ }^{\circ} \mathrm{C}$ ) and terminated by a supersonic nozzle. Ions are produced by an alternating current corona discharge located in the supersonic expansion zone close to the throat of the nozzle and are immediately taken up on tiny aerosols formed by water condensation. This avoids the attraction of charge carriers to the walls of the vessel by electric forces. Aerosols carrying the charges are ejected from the nozzle at high speed and evaporate at about $30 \mathrm{~cm}$ from the nozzle and release their charges in the form of ions. The electrostatic charge eliminator is fed with compressed air at 6 bar (flow rate of $12 \mathrm{~N} \mathrm{~m}^{3} \mathrm{~h}^{-1}$ ) and uses a $7-\mathrm{kV}$ rms highvoltage power supplies. The patented device delivers $8 \mu \mathrm{A}$ of negative and positive current in equal amounts of positive and negative ions. Unlike conventional active corona eliminators, the charges carried by the supersonic jet can discharge targets up to a few meters from the nozzle [9].

The water consumption of the eliminator is low and leads to a relative humidity inferior than $5 \%$. Consequently, this

Table 1

Characteristics of the particles

$d(0.1)(\mu \mathrm{m}) d(0.5)(\mu \mathrm{m}) d(0.9)(\mu \mathrm{m}) \quad D(\mu \mathrm{m})[2,3]$

\begin{tabular}{lllll}
\hline Polyethylene powder & 465 & 801 & 1381 & 869
\end{tabular}


water alone cannot eliminate static electricity. The eliminator is located in the metallic part of the fluidised bed which allows its angle $(\theta)$ to be varied (Fig. 2) between $0^{\circ}$ and $45^{\circ}$ to the horizontal. It is not possible to put it below the distributor because aerosols and ions would be stopped before going inside the column. Moreover, if the eliminator is put at the column wall, most aerosols would not have enough time to melt before their collision with the wall, and the hydrodynamic of the bed would be strongly modified by the air of the eliminator.

The fluidised particles are low-density polyethylene granules and powder of $920 \mathrm{~kg} \mathrm{~m}^{-3}$ density. The granules are $3 \mathrm{~mm}$ in diameter. The particle size distribution of the
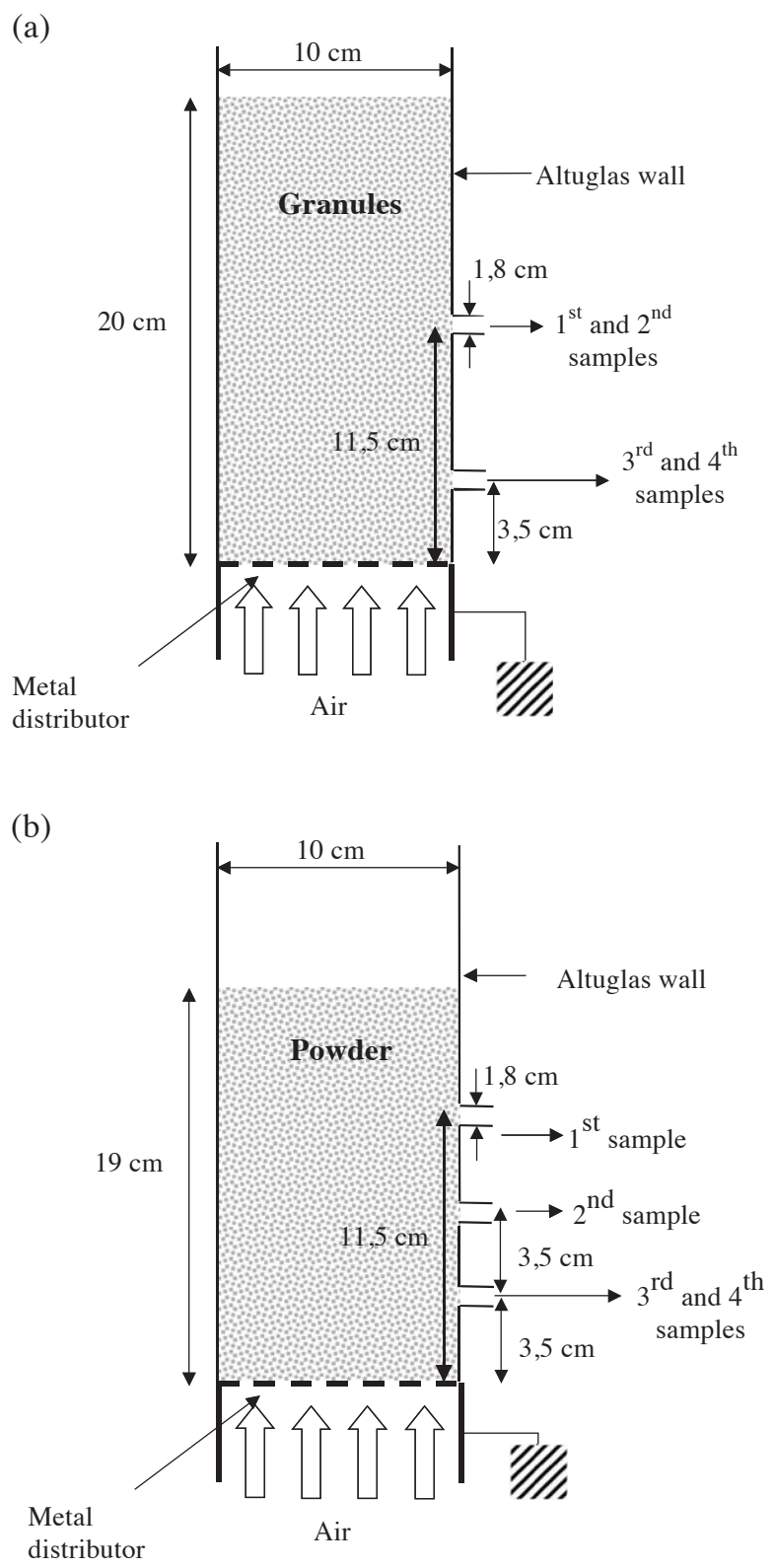

Fig. 3. Location of the samples for the charge-to-mass measurements of granules (a) and of powder (b). powder (expressed in terms of surface) is shown in Table 1 where $D[2,3]$ represents the surface/volume diameter and $d(0.5)$ is the diameter which cut the total surface of particles in two equal parts. All products belong to group D of the Geldart classification [10]. In all experiments, the total mass of granules used is $890 \mathrm{~g}$ in order to have a packed bed height equal to twice the column diameter $(20 \mathrm{~cm})$. However, because of problems with elutriation, less material is used in the experiments with the powder. The packed bed height of powder is $19 \mathrm{~cm}$ corresponding to $410 \mathrm{~g}$.

The degree of electrification reached by the bed during fluidisation is defined by the measurement of the net chargeto-mass ratio $(\mathrm{Q} / \mathrm{m})$ of the particles which is determined by means of a Faraday pail connected to an electrometer and by weighing the particles.

In order to measure it, four samples are taken at various locations in the particle bed. To do this, fluidisation is stopped and a total of approximately $10 \%$ of the total mass of particles are removed from different heights near the column wall (S in Figs. 1 and 2). For the granules (Fig. 3a), two samples are taken successively at $11.5-\mathrm{cm}$ height above the distributor and two other samples at $3.5 \mathrm{~cm}$ above the distributor. For the powder (Fig. 3b), the first sample is taken at $11.5-\mathrm{cm}$ height above the distributor. The second sample was taken at 7-cm height above the distributor since the powder level is too low for sampling at $11.5 \mathrm{~cm}$. The third and fourth samples are taken at $3.5 \mathrm{~cm}$ above the distributor. Samples are removed by supplying the fluidised bed with a little flow of air so as to eject the particles, which then fall directly into the Faraday pail. After charge determination and weighing, the samples are put back in the column and are fluidised again.

\section{Results and discussion}

\subsection{Hydrodynamic}

To maintain similar hydrodynamic conditions in all the experiments, the eliminator is always supplied with air and only the power supply is switched off and on to test charging and discharging conditions. In the experiments with granules, the eliminator is set at an angle of $45^{\circ}$ to the horizontal. With the powder, the angle is $10^{\circ}$ to the horizontal, so as to limit elutriation. The small diameter of the column and the fluidising properties of the granules lead to large bubbles called slugs, which completely fill the column [11]. In the case of powder, bubbles do not completely fill the column, but the upper surface of the bed has a piston-like movement. The minimum fluidisation velocity $\left(u_{\mathrm{mf}}\right)$ for initially discharged granules and powder are 1 and $0.31 \mathrm{~m} \mathrm{~s}^{-1}$, respectively.

In order to study the influence of static electricity on the minimum fluidisation velocity $\left(u_{\mathrm{mf}}\right)$, this measurement has been made with granules and powder, which were initially charged. Results show that the difference between the $u_{\mathrm{mf}}$ 
measured with charged and discharged particles is not significant. Consequently, in our case, this minimum fluidisation velocity is not influenced by the electrostatic charges of the particles.

\subsection{Electrostatic behaviour}

The electrostatic behaviour of the two products was studied in order to set the influence of the particles size on their electrification.

\subsubsection{Granules}

The evolution of the charge-to-mass ratio of granules with fluidisation time $(t)$ for the four samples is shown in Fig. 4. The charge-to-mass ratio was measured every minute, and each point is an average of five experiments made under the same conditions. In order to generate electrification, the fluidisation velocity is chosen equal to $2.5 u_{\mathrm{mf}}$, which induces strong motion of granules in the fluidised bed. Granules are ejected in the metallic disengagement zone and rain back down into the column.

The charge-to-mass ratio for the four-granule samples increases (in absolute value) with fluidisation time and reaches a saturation charge level. Triboelectrification can be attributed to particle-wall interactions in the column and in the bed freeboard. The charge-to-mass ratio of polyethylene particles is negative because the work function of Altuglas ${ }^{\circledR}$ and stainless steel is lower than that of polyethylene. We assume that the bed walls become positively charged. The saturation charge level could be a function of both charge generation and charge dissipation processes. As low-density polyethylene has an extremely high resistivity, ohmic dissipation during contact time with the walls can be neglected. Moreover, the relative humidity inside the fluidised bed is about 5\% and therefore does not encourage charges flowing to earth. An explanation of this loss of electric charge could be due to local air ionisation by corona discharges. These discharges can appear if the electrical breakdown field of air $E_{\mathrm{d}}(3 \mathrm{MV} / \mathrm{m}$ under normal conditions [12]) is locally exceeded. Gauss's theorem gives an upper bound of the limit charge (before discharge) in our system. The maximum charge-to-mass ratio $Q / m$, which can be tolerated before discharge, initiated in a cylinder of diameter $D$ and height $H$ containing a mass $M$ of polyethylene granules, is given by:

$\left|\frac{Q}{m}\right|_{\max }=\frac{\pi \varepsilon_{0} E_{\mathrm{d}} D H}{M}$

For a diameter of $0.1 \mathrm{~m}$, height of $0.2 \mathrm{~m}$ and $0.89 \mathrm{~kg}$ of granules, the maximum charge-to-mass ratio of granules is $1.8 \mu \mathrm{C} / \mathrm{kg}$. This value is of the same order as the saturation charge level obtained in Fig. 4.

Moreover, particles have negative charges and the bed walls become positively charged. This means that some particles can adhere to the bed walls, reducing the contact surface between particles and bed, and so slowing down the particles charge acquisition. Actually, during experiments, we observed that some granules adhere strongly to the lower part of the column wall when the fluidisation time is greater than $5 \mathrm{~min}$. The charge-to-mass ratio of the third sample is higher than the others because some granules which were removed are those which were sticking to the column wall (Fig. 3). Another consequence is that attraction strengths between the particles and the bed walls become stronger with the fluidisation time, increasing the particles bulk cohesion leading to less particles-wall interactions. In fact, during experiments, the four sample values are close to each other during the increase of the charge-to-mass with fluidisation time, which means that the homogenisation inside the column is good. But the difference between these values emphasises when the saturation charge level is reached (see Fig. 5) which means that the axial mixing is not well assured when granules are highly charged. This is surely a consequence of the bulk electrostatic cohesion, and this could be another explanation of the slowing down of the charge acquisition.

Reproducibility of these experiments has been studied and is shown in Fig. 5. Each data point represents the average of the first sample of five experiments performed in

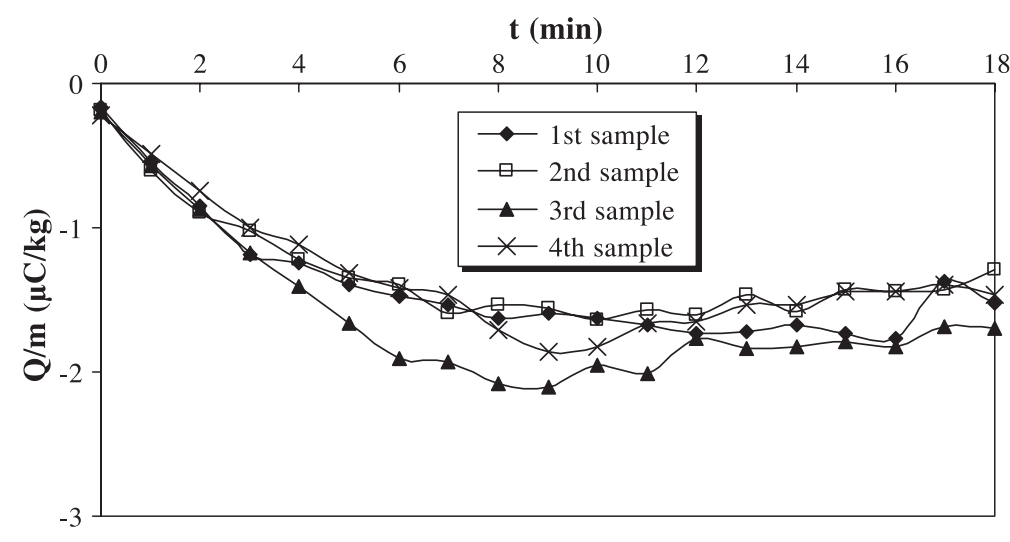

Fig. 4. Charge-to-mass ratio for granules with fluidisation time at $2.5 u_{\mathrm{mf}}$. 


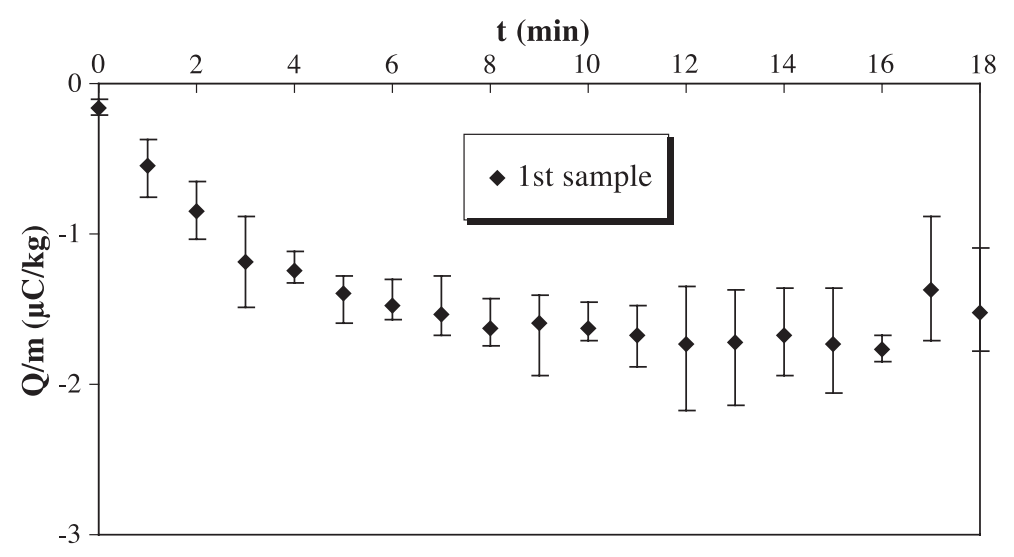

Fig. 5. Charge-to-mass ratio of the first sample of granules with fluidisation time at $2.5 u_{\mathrm{mf}}$.

the same conditions. The scatter limits are shown. The reproducibility decreases when the saturation charge level is reached. Similar results are obtained with other samples. This can be attributed to the nonreproducibility of the statistics of the discharges occurring when the granules are highly charged and the poor axial mixing in the electrified bed of particles.

In order to evaluate the influence of fluidisation velocity on electrification in the fluidised bed, two other fluidisation velocities were used: $1.7 u_{\mathrm{mf}}$ and $2.1 u_{\mathrm{mf}}$. The first was chosen because under these conditions, the granules stay in the column and are not ejected into the upper metal part of the fluidised bed (disengagement zone). Nevertheless, slugs are formed with all the three velocities. Fig. 6 shows the evolution of the charge-to-mass ratio with fluidisation time of the first sample for the three fluidisation velocities. The charge-to-mass ratio of the granules for $1.7 u_{\mathrm{mf}}$ and $2.1 u_{\mathrm{mf}}$ increases less rapidly than for $2.5 u_{\mathrm{mf}}$. This is because the granule motion in the fluidised bed is less vigorous. Nevertheless, the same saturation charge level is reached for the three velocities and granules stick to the lower part of the column. Similar results are obtained for the other samples.

In conclusion, the charge-to-mass ratio for the four samples of granules increases (in absolute value) with fluidisation time and reaches a saturation charge level, which is function of both charge generation and charge limitation processes. Charge generation is due to contacts between polyethylene particles and the walls of the installation, while corona discharges or the reduction of the contacts number and the increase of strengths between particles and walls could explain the charge limitation. Moreover, the saturation level is more rapidly reached when the air fluidisation velocity is high.

\subsubsection{Powder}

Charge-to-mass ratio of powder with fluidisation time was followed as for the granules. The fluidisation velocity is $1.6 u_{\mathrm{mf}}$ and the eliminator angle is $10^{\circ}$ to the horizontal. This configuration allows the powder to stay in the column and limits elutriation. Results are shown in Fig. 7.

The charge-to-mass ratio increases with fluidisation time and a saturation charge level is reached. Powder particles tend to adhere to the surface of the column very soon after the start of fluidisation. When fluidisation is stopped, particles can be observed to be sticking to the column wall above the packed bed. The presence of a saturation charge level can be explained by the fact that because of the particle adhesion to the wall, there is less polyethylene-Altuglas ${ }^{\circledR}$ interactions. Moreover, important differences can be seen between the charge-to-mass ratio of the four samples. The

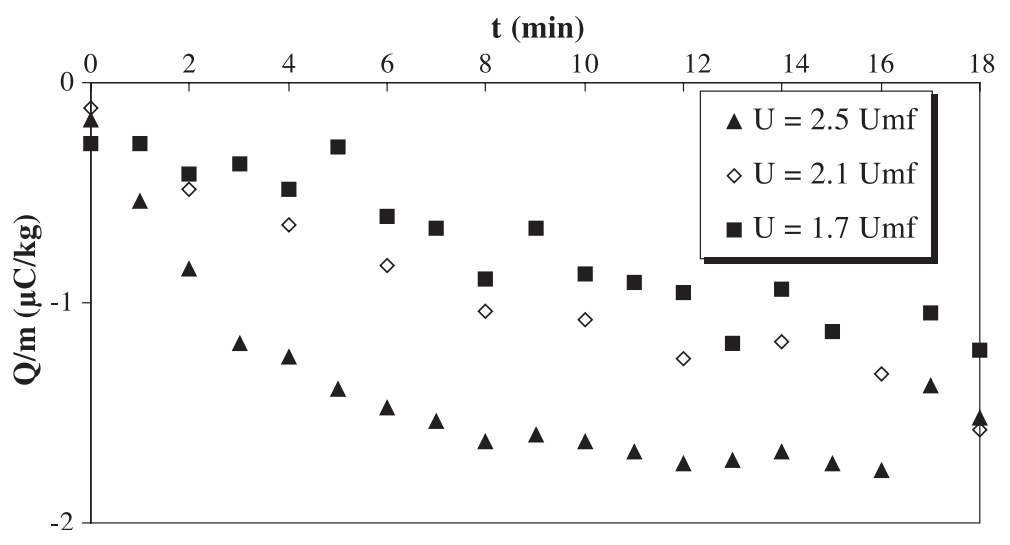

Fig. 6. Charge-to-mass ratio of the first sample of granules with fluidisation time for three fluidisation velocities. 


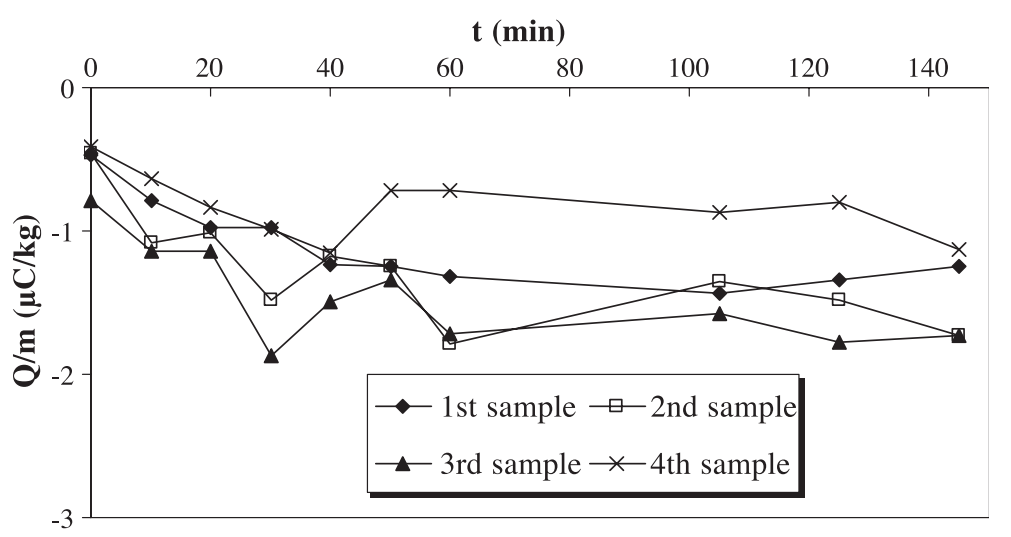

Fig. 7. Charge-to-mass ratio of powder with fluidisation time at $1.6 u_{\mathrm{mf}}$.

third sample is more charged than the others are. These differences are emphasised with time, as the charge-to-mass ratio increases. This is the result of a poor axial mixing due to electrostatic bed cohesion.

\subsubsection{Discussion}

The use of the two products allowed studying the electrostatic behaviour for different sizes of polyethylene particles. The results showed that the evolution of the charge-to-mass ratio with fluidisation time was similar for granules and powder. Indeed, the charge-to-mass ratio of the two products increased with fluidisation time and reached a saturation charge level, which was function of both charge generation and limitation processes.

Moreover, the total charge of granules particles $(-1.3$ $\mu \mathrm{C})$ is higher than that of powder $(-0.6 \mu \mathrm{C})$. This is the same thing if we consider the charge-to-surface ratio, showing that, in respect with their small size, powder particles are less charged during fluidisation at $1.6 u_{\mathrm{mf}}$ $\left(-0.22 \mu \mathrm{C} / \mathrm{m}^{2}\right)$ than granule ones at $1.7 u_{\mathrm{mf}}(-0.94 \mu \mathrm{C} /$ $\mathrm{m}^{2}$ ). Indeed, the contact surface area is smaller with powder than with granules because more particles adhere to the

(a)

(a) $\quad \mathbf{m i n}$ (m)

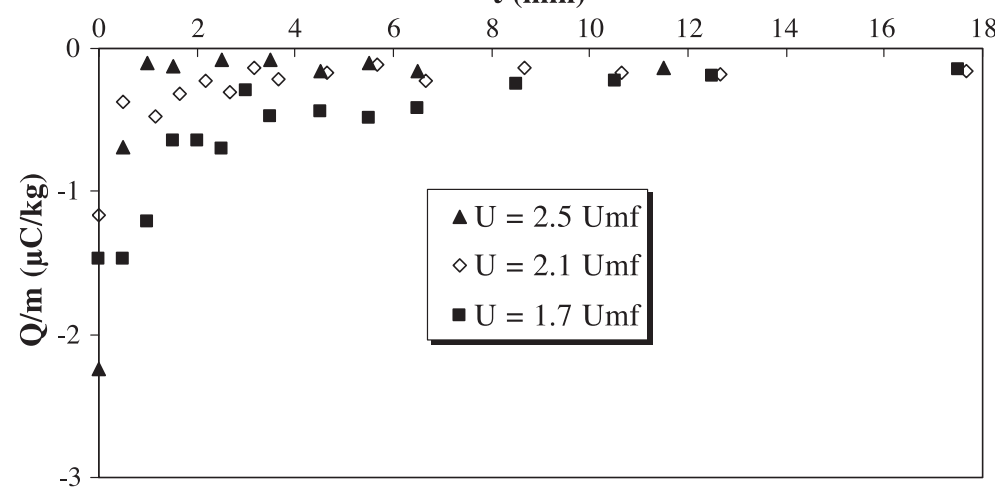

(b)

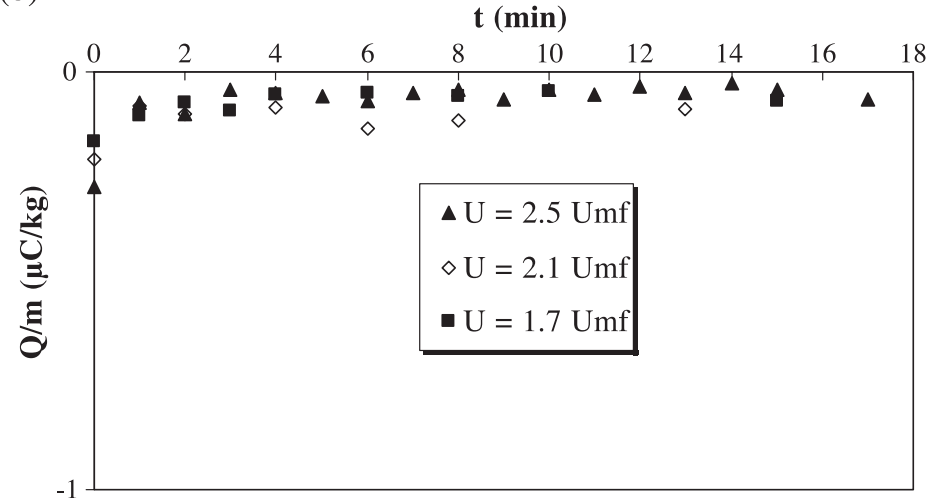

Fig. 8. Charge-to-mass ratio of granules of the first sample with fluidisation time for the three fluidisation velocities with initially charged granules (a) and discharged granules (b). 
column walls. Moreover, collisions between particles and walls are more energetic in the case of granules.

\subsection{Effect of the eliminator}

It has been shown that the fluidised bed can generate significant electrification. The influence of the static charge eliminator has been studied by repeating the experiments with the high voltage switched on in order to produce ions. The electric field resulting from positives charges of the column walls and negative charges of particles attracts ions of opposite polarity. The earth-connected metal walls of the equipment capture the excess of ions ejected from the eliminator.

\subsubsection{Granules}

Using the same experimental protocol as above, the charge-to-mass ratio has been sampled for the three fluidisation velocities $\left(1.7 u_{\mathrm{mf}}, 2.1 u_{\mathrm{mf}}\right.$ and $\left.2.5 u_{\mathrm{mf}}\right)$. The eliminator angle is $45^{\circ}$ and the supersonic jet is pointed toward the centre of the column. Fig. 8 shows the variation of the chargeto-mass ratio with fluidisation time of the first sample, for the three fluidisation velocities, starting with both initially charged granules (a) and initially discharged granules (b). The effect of the eliminator angle has also been studied for 1.7 $u_{\mathrm{mf}}$ for initially charged granules. Three angles have been used: $35^{\circ}, 25^{\circ}$ and $10^{\circ}$ to the horizontal. The results obtained for the four samples are shown in Fig. 9.
In the presence of ions, the absolute value of the chargeto-mass ratio of polyethylene granules decreases with fluidisation time for all three fluidisation velocities. In less than 3 min, the charge-to-mass ratio reaches an absolute value less than $0.5 \mu \mathrm{C} / \mathrm{kg}$. Furthermore, in the presence of ions, there are fewer oscillations of the charge-to-mass ratio values. This may perhaps be due to the absence of discharges in the fluidised bed and a better axial homogenisation of granules. When the system is sufficiently discharged, the layer of granules adhering to the column wall disappears.

Moreover, the higher the fluidisation speed is, the faster the neutralisation of the static charge is (Fig. 8a). On the one hand, this is due to the fact that for a fluidisation speed higher than $1.7 \mathrm{~m} \mathrm{~s}^{-1}$, granules are ejected in the disengagement zone. They then have better accessibility to ions, firstly because granules are more separated out, and secondly because they have a longer residence time in the ion cloud. In addition, the greater the velocity of fluidisation, the shorter is the turnover time of the fluidised beds [11]. For velocities of $1.7 u_{\mathrm{mf}}, 2.1 u_{\mathrm{mf}}$ and $2.5 u_{\mathrm{mf}}$, the turnover times are 248, 148 and $115 \mathrm{~s}$, respectively.

With initially discharged granules (Fig. 8b), their chargeto-mass ratio remains near zero for all three fluidisation velocities. The same results were obtained for the other samples.

Concerning the effect of the eliminator angle, the results obtained at $1.7 u_{\mathrm{mf}}$ show that the lower the angle of the eliminator to the horizontal is, the poorer is the neutralisa- (a)

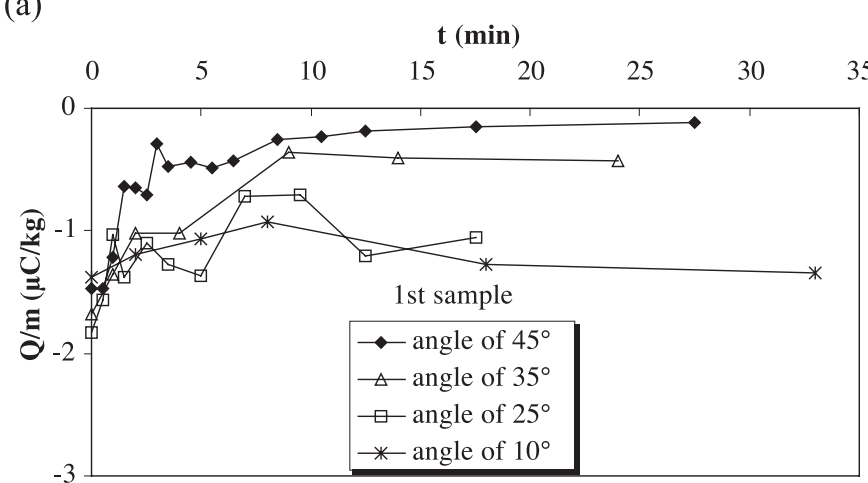

(b)

\begin{tabular}{llllllll}
\multicolumn{9}{c}{$\mathbf{t}(\mathbf{m i n})$} \\
& 0 & 5 & 10 & $15^{20}$ & 25 & 30 & 35
\end{tabular}

(c)

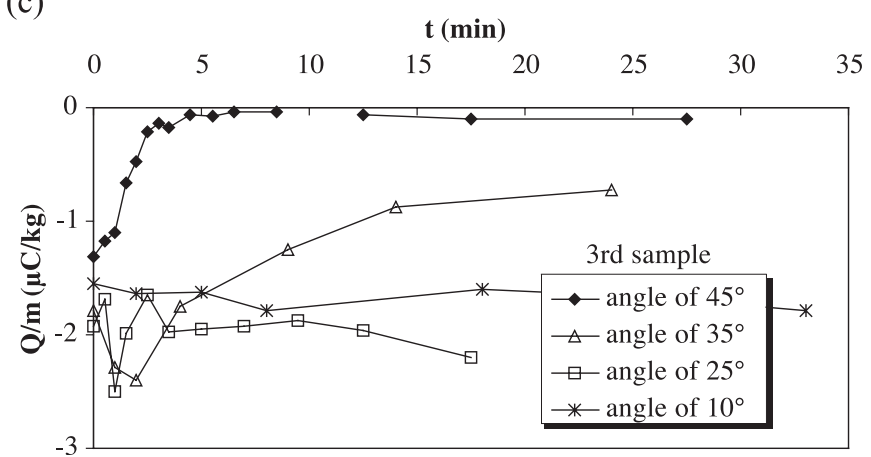

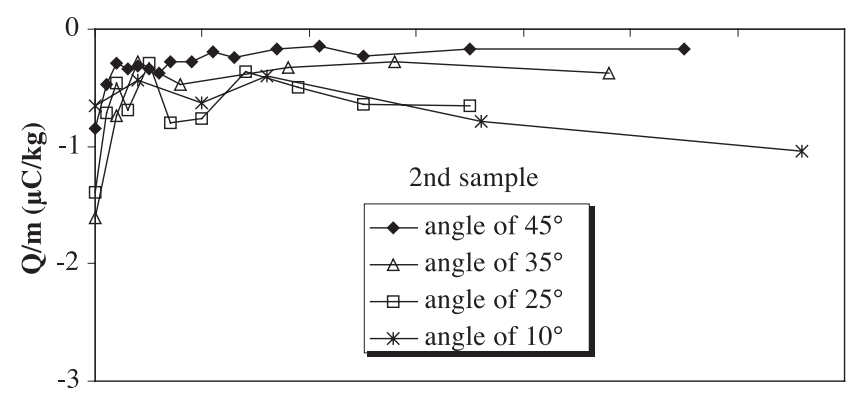

(d)

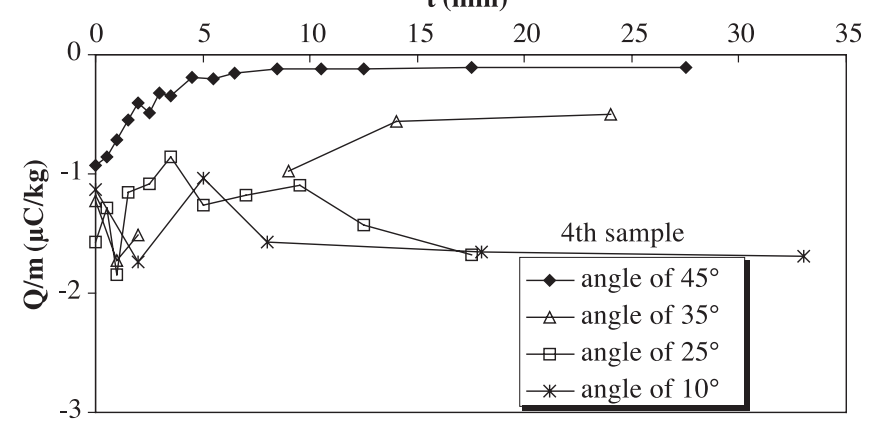

Fig. 9. Charge-to-mass ratio of the granules with fluidisation time at $1.7 u_{\mathrm{mf}}$ for different eliminator angles for the first sample (a), second sample (b), third sample (c) and fourth sample (d). 
tion. For angles less than $45^{\circ}$, the charge-to-mass ratios of the third and fourth samples (Fig. 9c and d), which correspond to granules situated in the lower part of the bed, are higher than the other samples (Fig. 9a and b). The higher charge in the lower part of the bed can be explained by the fact that the mixing conditions are poor and bulk turnover is reduced. Indeed, for angles less than $45^{\circ}$, the particles movement is slower due to a lower turbulence created by the air introduced by the eliminator. This further suggests that ions do not penetrate in the bed and that only the upper particles of the bed are neutralised.

\subsubsection{Powder}

Fluidisation velocity is $1.6 u_{\mathrm{mf}}$ and the angle of the eliminator probe is maintained to $10^{\circ}$ to the horizontal because the use of a greater angle would lead to too much elutriation. As reported in the precedent section, this configuration leads to a poor axial mixing.

Results of the experiments using the eliminator with powder are shown in Fig. 10 both for an initially charged powder (a) and an initially discharged powder (b). The charge-to-mass ratio of initially charged material decreases slightly (in absolute value) with fluidisation time, and the particle layer still remains attached to the column wall. When the powder is initially discharged, the ions produced by the eliminator do not limit the charge-to-mass ratio and the eliminator does not prevent sticking. Only the first sample is neutralised, which demonstrates that axial mixing is poor and that ions do not penetrate in the bulk.

\subsubsection{Discussion}

It seems that ions do not penetrate the bed of particles and therefore only reach particles at the upper surface of the fluidised bed. Indeed, with the hypothesis that granules and powder are ideally fluidised in the column with a bed height of $30 \mathrm{~cm}$, the free path of the ions in the fluidised bed can be roughly calculated (without taking gravity and electrostatic force effects into account) [13]. In the case treated here, the free path of the ions in the bed of granules and powder B would be 4.8 and $2.9 \mathrm{~mm}$, respectively. Consequently, the renewal of the upper surface of the fluidised bed seems to be the only way for contacting ions and particles. Particles have to be present at the upper surface of the bed, that is to say, in contact with the ion cloud in order to be neutralised. This depends on the quality of the fluidisation.

For the granules, this can explain the difference in discharge as a function of fluidisation velocity and eliminator angle. The greater is the fluidisation velocity, the faster the bed surface is renewed (lower turnover time), which partly explains why discharging is faster. When the angle of the eliminator is $45^{\circ}$ and $35^{\circ}$, the airflow causes the granules to move a lot and the discharge is efficient. In this case, the granules surface is often renewed due to the air from the eliminator creating turbulence. When the angles

(a)

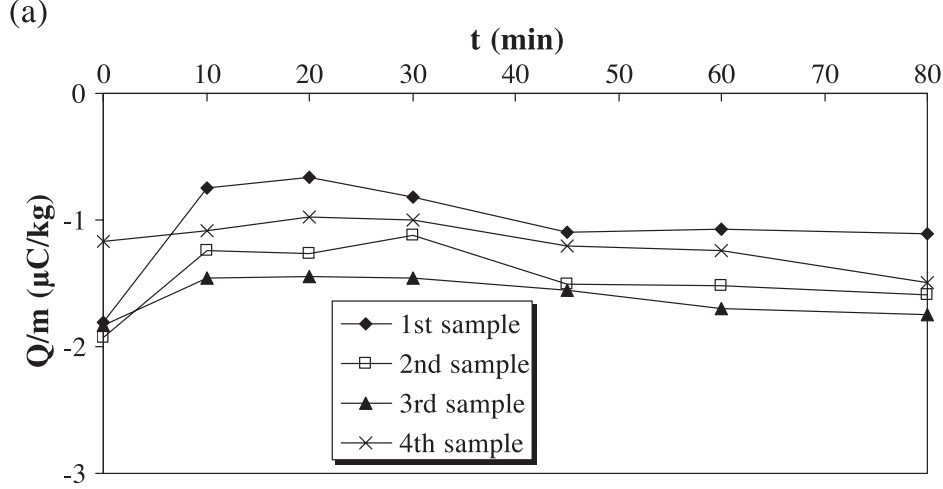

(b)

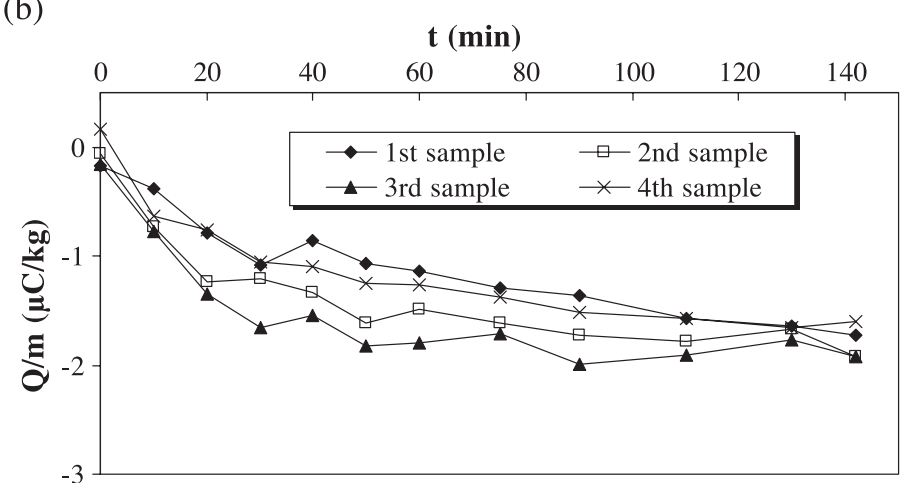

Fig. 10. Charge-to-mass ratio of powder B with fluidisation time for the four samples with initially charged powder (a) and discharged powder (b). 
are $25^{\circ}$ and $10^{\circ}$, the discharge is inefficient because the granule movement is less and the bed surface is not well renewed. Furthermore, for higher fluidisation speeds and eliminator angles, particles are ejected in the disengagement zone and the ion free path is more important.

Experiments with powder were conducted at $1.6 u_{\mathrm{mf}}$ and $10^{\circ}$ and can be compared to that with granules at $1.7 u_{\mathrm{mf}}$ and $10^{\circ}$. This shows that particles neutralisation seems to not depend on particle size but roughly on bed dynamics. Finally, it should be interesting to work under different fluidisation conditions in order to emphasise the importance of bed dynamics on particle neutralisation.

\section{Conclusion}

The fluidisation of polyethylene particles generates a lot of static electricity because of the great number of particlewall and particle-particle contacts both in the column and in the disengagement zone. It has been found that the evolution of the net charge-to-mass ratio, which is always negative, is similar for the granules and the powder studied. The charge-to-mass ratio increases (in absolute value) during fluidisation to reach a saturation level, which is more rapidly reached for the granules when the air fluidisation velocity is high. The charge saturation level is a function of both charge generation and charge limitation processes. In the case treated here, static electricity is found not to influence the minimum fluidisation velocity.

The efficiency of static charge eliminator delivering a neutral cloud of ions above the fluidised bed has been studied for polyethylene granules and powder. The results show that efficiency of charge elimination depends on the accessibility of particles. Indeed, ions do not penetrate in the fluidised particle bed, and only the particles on the upper surface of the bed are discharged, thus indicating the importance of the renewal of the upper surface of the fluidised bed for application of this technique in charge neutralisation. Working with bubbling fluidisation, and so with a better axial mixing of particles, should improve the neutralisation process. This will be the subject of a next work.

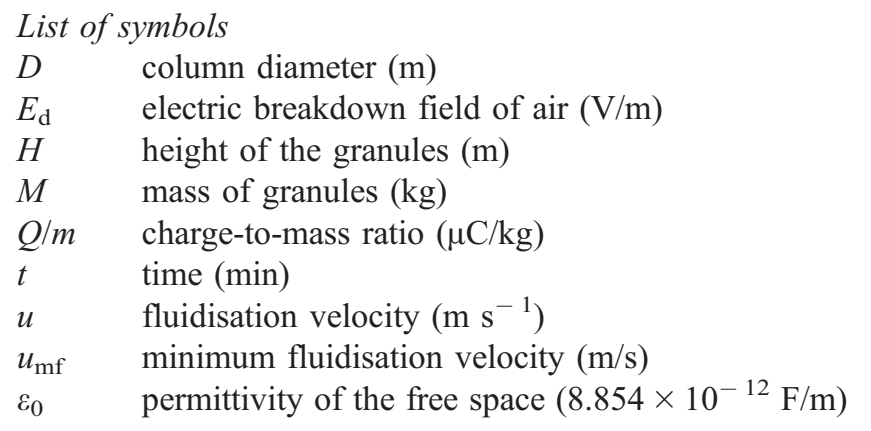

\section{References}

[1] C.O. Miller, A.K. Logwinuk, Fluidisation studies of solid particles, Industrial and Engineering Chemistry 43 (1951) 1220.

[2] D. Boland, D. Geldart, Electrostatic charging in gas fluidized beds, Powder Technology 5 (1971-1972) 289.

[3] A. Wolny, W. Kazmierczak, The influence of static electrification on dynamics and rheology of fluidized bed, Chemical Engineering Science 48 (1993) 3529.

[4] A. Wolny, I. Opalinski, Heat transfer in an electrostatically charged fluidized bed, International Journal of Heat and Mass Transfer 27 (1984) 2037.

[5] A. Wolny, I. Opalinski, Electric charge neutralization by addition of fines to a fluidized bed composed of coarse dielectric particles, Journal of Electrostatics 14 (1983) 279.

[6] J. Ciborowski, A. Wlodarski, On electrostatic effects in fluidized beds, Chemical Engineering Science 17 (1962) 23.

[7] J. Guardiola, V. Rojo, G. Ramos, Influence of particle size, fluidisation velocity and relative humidity on fluidized bed electrostatics, Journal of Electrostatics 37 (1996) 1.

[8] A. Wolny, W. Kazmierczak, Triboelectrification in fluidized bed of polystyrene, Chemical Engineering Science 44 (1989) 2607.

[9] J. Taillet, Applications of supersonic injection of electric charges in chemical engineering, Journal of Electrostatics 40\&41 (1997) 265.

[10] D. Geldart, Types of gas fluidisation, Powder Technology 7 (1973) 285.

[11] D. Geldart, Gas Fluidisation Technology, Wiley, Chichester, 1986.

[12] A.G. Bailey, Electrostatic phenomena during powder handling, Powder Technology 37 (1984) 71.

[13] E. Nasser, Fundamentals of Gaseous Ionization and Plasma Electronics, Wiley Interscience, New York, 1971. 